\title{
COMPARISON OF PROPOFOL/DEXMEDETOMIDINE FOR ASLEEP AWAKE ASLEEP TECHNIQUE FOR AWAKE CRANIOTOMIES IN TERTIARY CARE HOSPITAL
}

\author{
Manisha S. Kapdi1 ${ }^{1}$ Rupal J. Shah'2, Shvangi Patel ${ }^{3}$, Manhar G. Vachhani ${ }^{4}$, Nidhi Patel ${ }^{5}$ \\ ${ }_{1}^{1}$ Associate Professor, Department of Anaesthesia, NHLM Medical College, Ahmedabad, Gujarat, India. \\ ${ }^{2}$ Associate Professor, Department of Anaesthesia, AMCMET College, Ahmedabad, Gujarat, India. \\ ${ }^{3}$ Resident, Department of Anaesthesia, NHLM Medical College, Ahmedabad, Gujarat, India. \\ ${ }^{4}$ Resident, Department of Anaesthesia, NHLM Medical College, Ahmedabad, Gujarat, India. \\ ${ }^{5}$ Resident, Department of Anaesthesia, NHLM Medical College, Ahmedabad, Gujarat, India.
}

\section{ABSTRACT}

\section{BACKGROUND}

Awake craniotomy is an important technique used for brain tumour excision from eloquent cortex, epilepsy foci removal surgery, deep brain stimulation, less commonly for mycotic aneurysms, A-V malformation near cortical areas.

Aims and Objectives- To access quality of brain mapping, haemodynamic stability, perioperative airway security, \& observation of adverse effects in propofol, dexmedetomidine groups for awake craniotomies.

Group Allocation- (Maintenance of anaesthesia in both groups was different as follows :)

Group A (Propofol Group): inj. propofol $6 \mathrm{mg} / \mathrm{kg} / \mathrm{hour}$ for $10 \mathrm{~min}$, then $4 \mathrm{mg} / \mathrm{kg} / \mathrm{hour}$. (n=25)

Group B (Dexmedetomidine group): Inj. dexmedetomidine $0.5 \mathrm{mg} / \mathrm{kg} / \mathrm{hour}(\mathrm{n}=25)$.

\section{MATERIALS \& METHODS}

This randomised double-blind comparative study of premedication- Inj. glycopyrrolate $0.04 \mathrm{mg} / \mathrm{kg}$, inj. ondansetron $0.08 \mathrm{mg} / \mathrm{kg} \&$ in fentanyl $1 \mathrm{mcg} / \mathrm{kg}$. Scalp block: scalp block was given with inj. Ropivacaine $0.5 \% 30 \mathrm{ml}$ to block supraorbital, supratrochlear, zygomatic temporal, auriculotemporal nerves, greater auricular, lesser auricular nerves in General Hospital, NHLM medical college, Ahmedabad, Gujarat, India.

Induction- Induction was done with inj. thiopentone 5 to $7 \mathrm{mg} / \mathrm{kg} \mathrm{IV}$.

Airway security- By i-gel (second generation laryngeal mask airway)

Maintenance-

In group A: inj. propofol $6 \mathrm{mg} / \mathrm{kg} /$ hour for first $10 \mathrm{~min}$ then $4 \mathrm{mg} / \mathrm{kg} / \mathrm{hour}$

In group B: inj. dexmedetomidine $1 \mathrm{mcg} / \mathrm{kg} /$ hour for first $10 \mathrm{~min}$ then $0.5 \mathrm{mcg} / \mathrm{kg} / \mathrm{hour}$

When neurosurgeon wanted to perform brain mapping, patient's i-gel was removed \& patients were managed with low dose of propofol \& dexmedetomidine in awake period, then further dose was increased in 3rd phase, that is asleep period.

\section{RESULTS}

NRS score of cortical mapping was comparable in both groups-

- In both groups haemodynamic variables were stable \& comparable.

- In group B better airway management \& less complications observed.

\section{CONCLUSION}

In AAA method for awake craniotomies, use of dexmedetomidine is a good alternative to propofol.

\section{KEYWORDS}

Awake Craniotomy, AAA Method, Dexmedetomidine, Propofol, i-gel, Scalp Block.

HOW TO CITE THIS ARTICLE: Kapdi MS, Shah RJ, Patel S, et al. Comparison of propofol/dexmedetomidine for asleep awake asleep technique for awake craniotomies in tertiary care hospital. J. Evolution Med. Dent. Sci. 2019;8(01):14-18, DOI: $10.14260 /$ jemds/2019/4

\section{BACKGROUND}

Awake craniotomy is popular since 2 decades. It is usually performed for epilepsy surgery, temporal lobectomy, which encroaches eloquent cortex, motor, speech areas, Deep brain stimulation, for AV malformation which needs intraoperative

'Financial or Other Competing Interest': None.

Submission 28-11-2018, Peer Review 23-12-2018,

Acceptance 31-12-2018, Published 07-01-2019.

Corresponding Author:

Dr. Manisha S. Kapdi,

Associate Professor,

Department of Anaesthesia,

NHLM Medical College,

Ahmedabad, Gujarat, India.

E-mail:manisha_kapdi@yahoo.com

DOI: $10.14260 /$ jemds/2019/4 functional testing, Cortical mapping, which requires patient to be awake.(1,2) Main advantage of awake surgery is to define limits of resection \& avoid Postoperative neurological deficits.

Maintaining patient's cooperation by provision of optimal analgesia, sedation, anxiolysis and comfortable position, achieving homeostasis with safe airway, adequate ventilation and hemodynamic stability, Ensure minimal interference with electrocortico graphic recording during mapping.

Main Objective of the study was to access Brain mapping by NRS scale, Haemodynamic Stability, \& adverse effects with both study drugs dexmedetomidine or propofol.

\section{MATERIALS AND METHODS}

This Randomised double-blind comparative study of 50 adult elective patients with mass near the eloquent area with ASA 
grade I \& II, Age group 18 to 60 years were selected for awake craniotomy. Patients were informed in detail about procedure. Proper counselling of each patient was done VS hospital, NHLM medical college, Ahmedabad, Gujarat, India

\section{Preoperative Assessment}

Through preoperative assessment \& psychological counselling was done day before surgery.

\begin{tabular}{|c|c|}
\hline Group A & $\begin{array}{l}\text { Propofol }-10 \mathrm{mg} / \mathrm{kg} / \mathrm{hour} \text { for first } 10 \text { mins \& then } \\
4 \mathrm{mg} / \mathrm{kg} / \text { hour }\end{array}$ \\
\hline Group B & $\begin{array}{l}\text { Dexmedetomidine- } / \mathrm{kg} / \mathrm{hour} \text { for first } 10 \text { mins and } \\
\text { then } 0.5 / \mathrm{mg} / \mathrm{kg} / \text { hour }\end{array}$ \\
\hline
\end{tabular}

\section{Group Allocation}

Group Allocation was done by using Randomisation table.(3)

Allocation concealment done by sealed opaque envelope. Envelope was opened just before General Anaesthesia administration to the patient.

\section{Sample Size}

The sample size for the study was taken for convenience.

\section{Premedication}

It was given in form of Inj. Glycopyrrolate $0.04 \mathrm{mg} / \mathrm{kg}$, Inj. Ondansetron $0.08 \mathrm{mg} / \mathrm{kg}$, and Inj. Fentanyl were given Intravenously.

Benzodiazepine premedication was avoided because of its residual sedative and amnesic effects during intra operative assessment phase.

\section{Pre-0xygenation}

02 mask was applied with $\mathrm{O}_{2}$ flow $4 \mathrm{~L} / \mathrm{min}$. Urinary catheter was inserted for patients comfort for long operative procedure and for diuretic administration. INJ. Cefazolin $1 \mathrm{gm}$ was given for infection prophylaxis.

\section{Scalp Block}

It was given by using Ropivacaine $0.5 \% .30 \mathrm{ml}$ (max.) to block supraorbital, supratrochlear, zygomaticotemporal, Auriculotemporal, greater \& lesser occipital, greater auricular nerves for better analgesia \& perioperative Haemodynamic stability. Patients were managed by ASLEEP AWAKE ASLEEP technique in following manner.

\section{Induction}

Patients were induced by Inj. thiopentone 5 to $7 \mathrm{mg} / \mathrm{kg}$ intravenously.

\section{Airway Security}

After induction, 2nd generation LMA (i-gel) of appropriate size was inserted, cuff inflated, bilateral air entry checked and after confirming air entry i-gel was fixed.

\section{Mode of Ventilation}

1. Patients were put on spontaneous plus assistance mode on ventilator Of Dragger Fabius GS work station

2. With i-gel EtCO2 sample line was attached to monitor EtCO2 intra operatively.

\section{Patients were maintained by (A sleep Period)}

By i-gel 02 (2 L/min) + N20 (2 L/min) + Sevoflurane (0.5-2\%) was started.

\section{Maintenance was Different in Both Groups-}

- In-Group A - Propofol infusion was started with loading dose of $6 \mathrm{mg} / \mathrm{kg} /$ hour over $10 \mathrm{~min}$, followed by 4 $\mathrm{mg} / \mathrm{kg} / \mathrm{hour}$

- In Group B - Dexmedetomidine infusion was started with loading dose of $/ \mathrm{kg}$ over $10 \mathrm{~min}$. followed by 0.5 $\mathrm{mcg} / \mathrm{kg} /$ hour.

\section{Position}

Patients were positioned in Right or Left Lateral position according to site of lesion in Sujita frame.

Sniffing position was achieved to help facilitate and patent airway. A tent was made under the drape to allow direct communication with patients when mapping was done $\&$ they were awake.

\section{Intra Operative Period: (Awake Period)}

After position, operation was started, perioperative Haemodynamic, respiratory, EtCO2, , SpO2 monitoring done periodically with interval of 15 mins and surgeons were told to inform $15 \mathrm{~min}$ before the craniotomy was expected to over, all inhalational agents were stopped in both groups, i-gel was removed and nasal prongs applied for oxygenation. At the end of prongs ETCO2 line (Side arm) was attached. In awake phase patients were oxygenated by nasal prongs. Sedation was managed in following ways: During awake phase patients were managed in different ways.

- In Group A (Propofol group) infusion was decreased to 2 $\mathrm{mg} / \mathrm{kg} /$ hour.

- In Group B (Dexmedetomidine group), it was decreased to $0.3 \mathrm{mcg} / \mathrm{kg} / \mathrm{hr}$.

In both groups, within 15 minutes after stopping inhalation agent patients were awake, conscious, and comfortable, i-gel was removed \& nasal prongs were applied for oxygenation. Patients were put on nasal prongs with 02 flow rate of $3 \mathrm{l} / \mathrm{min}$.

Perioperative Haemodynamic respiratory variables noted periodically in form of HR, Mean Arterial pressure (MAP), SPO2, ETCO2.

Peroperative awareness was assessed by PRST score (Pressure, Heart Rate, Sweating, Tears in each parameter there is sub score of $0,1,2) 0-4$ score is good as patient has depth of anaesthesia, $>4$ grade suggest awareness. BIS was only available for 5 patients of group B \& 5 patients of group A technique. It was managed between 60-70.(4)

Rescue fentanyl $50 \mathrm{mcg}$ was given for further analgesia. After patients were fully awaked, when neuro surgeon performed speech testing and cortical mapping (language, motor tone of limbs, speech testing). Motor strength was tested by asking patients to move their fingers, dorsiflexion of toes against resistance. Patients advised to note change in sensation. Language was tested by asking patients to count or name list of objects \& observe their speech arrestor hesitation.

\section{Cortical Mapping(1)}

- It was done according to NRS scale. NRS scale of 0 is worst mapping, \& 10 is excellent. NRS scale $>7$ was considered satisfactory.

- Patients were watched for adverse reactions like convulsion, respiratory depression, tight brain at the site of operation, hypercapnia, and bradycardia, Nausea, Vomiting. 


\section{After Mapping: (Asleep Period)}

- $\quad$ Patients were asleep in both groups in following manner Without i-gel. (Dose of both study drugs increased to make patients asleep for closure of craniotomy)

- In group A Propofol Infusion was increased to $4 \mathrm{mg} / \mathrm{kg} /$ hour

- In group B Dexmedetomidine infusion was increase to $0.5 \mathrm{mcg} / \mathrm{kg} / \mathrm{hr}$

- After the resection of tumour remaining surgery was conducted with same rate. At the end.

- At timeline of skin closure, Dexmedetomidine/ Propofol infusion was stopped.

\section{Postoperative Monitoring of Recovery}

- It was accessed with Modified Aldrete score. (MAS)(5)

- When patients in both groups MAS of more then 7 they were shifted to postoperative recovery ward.

- Post operative course of patients was noticed in form of vitals, complications, mean hospital stay in days. Patient satisfaction score (Satisfactory, Good, Excellent), surgeon satisfaction score (Satisfactory, Good, Excellent) were noticed by Linkert scale.

\section{Primary Outcome}

It was ability to perform cortical Mapping.

\section{Secondary Outcome}

It was complications, patient satisfaction score, surgeon satisfaction score regarding Anaesthesia technique.

\section{Statistical Analysis}

- Observations were entered into Microsoft Excel, \& analysed by SPSS SOFTWARE 16(IBM, Arnmonk, NY, USA)

- Data were expressed as mean, range, standard deviations. Categorial data were expressed as their measures (no., $\mathrm{N}, \%$ ).

- Unpaired t test used for Numerical values.

- Chi - square test, was used for assessment of categorical data.

- $\quad p>0.05$ is non-significant (NS)

- $\mathrm{p}<0.05$ is significant(S).

- $\mathrm{p}<0.001$ is highly significant (HS)

\section{RESULTS}

\begin{tabular}{|c|c|c|c|}
\hline Parameters & Group A (n=25) & Group B (n=25) & p-Value (Inference) \\
\hline Age (Years) & $44+/-12$ & $42+/-14$ & $>0.05(\mathrm{NS})$ \\
\hline Sex (M/F) & $18: 7(72 \%: 28 \%)$ & $17: 8(68 \%: 32 \%)$ & $>0.05(\mathrm{NS})$ \\
\hline ASA Grade (I/II) & $15: 10(60 \%: 40)$ & $14: 11(56 \%: 44)$ & $>0.05(\mathrm{NS})$ \\
\hline Duration of surgery (mins) & $125+/-10$ & $120+/ 15$ & $>0.05(\mathrm{NS})$ \\
\hline \multicolumn{3}{|c|}{ Table 1. Demographic Data } \\
\hline
\end{tabular}

\begin{tabular}{|c|c|c|c|c|c|c|}
\hline Time & $\begin{array}{c}\text { HR } \\
\text { mean+/-SD } \\
\text { (Group A) } \\
(\mathbf{n = 2 5 )}\end{array}$ & $\begin{array}{c}\text { HR } \\
\text { mean+/-SD } \\
\text { (Group B) } \\
\text { (n=25) }\end{array}$ & $\begin{array}{c}\text { P value } \\
\text { (Inference) } \\
\text { For HR }\end{array}$ & $\begin{array}{c}\text { MAP } \\
\text { mean+/-SD } \\
\text { (Group A) } \\
\text { (n=25) }\end{array}$ & $\begin{array}{c}\text { MAP } \\
\text { mean+/-SD } \\
\text { (Group B) } \\
\text { (n=25) }\end{array}$ & $\begin{array}{c}\text { p value } \\
\text { (Inference) } \\
\text { For MAP }\end{array}$ \\
\hline $0 \mathrm{~min}$ & $100+/-12$ & $100+/-14$ & $>0.05(\mathrm{NS})$ & $100+/-6$ & $100+/-2$ & $>0.05(\mathrm{NS})$ \\
\hline $15 \mathrm{~min}$. & $90+/-14$ & $88+/-12$ & $>0.05(\mathrm{NS})$ & $98+/-4$ & $96+/-4$ & $>0.05(\mathrm{NS})$ \\
\hline $30 \mathrm{~min}$ & $88+/-12$ & $86+/-14$ & $>0.05(\mathrm{NS})$ & $96+/-2$ & $94+/-2$ & $>0.05(\mathrm{NS})$ \\
\hline $45 \mathrm{~min}$ & $78+/-12$ & $76+/-14$ & $>0.05(\mathrm{NS})$ & $96+/-4$ & $96+/-2$ & $>0.05(\mathrm{NS})$ \\
\hline $60 \mathrm{~min}$ & $77+/-13$ & $78+/-12$ & $>0.05(\mathrm{NS})$ & $92+/-6$ & $92+/-4$ & $>0.05(\mathrm{NS})$ \\
\hline $75 \mathrm{~min}$ & $88+/-14$ & $86+/-12$ & $>0.05(\mathrm{NS})$ & $90+/-2$ & $90+/-2$ & $>0.05(\mathrm{NS})$ \\
\hline $90 \mathrm{~min}$ & $84+/-16$ & $84+/-14$ & $>0.05(\mathrm{NS})$ & $90+/-4$ & $90+/-2$ & $>0.05(\mathrm{NS})$ \\
\hline $120 \mathrm{~min}$ & $86+/-16$ & $84+/-16$ & $>0.05(\mathrm{NS})$ & $90+/-2$ & $88+/-4$ & $>0.05(\mathrm{NS})$ \\
\hline $150 \mathrm{~min}$ & $82+/-14$ & $80+/-14$ & $>0.05(\mathrm{NS})$ & $92+/-4$ & $92+/-2$ & $>0.05(\mathrm{NS})$ \\
\hline $180 \mathrm{~min}$ & $80+/-12$ & $80+/-14$ & $>0.05(\mathrm{NS})$ & $100+/-4$ & $100+/-2$ & $>0.05(\mathrm{NS})$ \\
\hline & \multicolumn{7}{|c|}{ Table 2. Haemodynamic Parameters } \\
\hline
\end{tabular}

\begin{tabular}{|c|c|c|c|}
\hline Parameters & Group A (n=25) & Group B (n=25) & P value \\
\hline SpO2 & $95+/-4$ & $98+/-2$ & $<0.05(\mathrm{~S})$ \\
\hline ETCO2 & $38+/-8$ & $32+/-6$ & $>0.05(\mathrm{~S})$ \\
\hline NRS scale & $9.2+/-0.3$ & $9.4+/-0.2$ & $>0.05(\mathrm{NS})$ \\
\hline \multicolumn{2}{|c|}{ Table 3. Perioperative Respiratory \& Cortical Mapping Monitoring (p<0.05) } \\
\hline * Patients EtCO 2 remain within limit ranging from 26 to 32 mm of Hg during entire operation in group B. \\
In group An EtCO2 was slight elevated. 4(16\%) patients of A group developed shortness of breath, anxiety, hypercapnia 46.7 mm \\
of Hg(mean) and desaturation of 91\%, they were managed by increase oxygenation, ask the patient to deep breath, , rescue \\
fentanyl 50 mcg. and decreasing infusion rate of propofol \\
* There was not a single episode of hypercarbia and respiratory depression, or desaturation in any of patients during entire \\
group B.
\end{tabular}




\begin{tabular}{|c|c|c|}
\hline Adverse Effects & Group A (n=25) & Group B (n=25) \\
\hline Hypercarbia & $4(16 \%)$ & $4(16 \%)$ \\
\hline Seizures & $7(28 \%)$ & $2(8 \%)$ \\
\hline Nausea & $2(8 \%)$ & $2(8 \%)$ \\
\hline Bradycardia & $2(8 \%)$ & - \\
\hline Tight brain & $10(40 \%)$ & Nil \\
\hline Awareness & Nil \\
\hline
\end{tabular}

* Intraoperative seizures were present in $4(16 \%)$ patients in group B, 7 patients (28\%) in group A., which was present during mapping due to touching of functional areas of cortex., stopped by cold saline irrigation

* Nausea and Bradycardia was present Perioperatively in 2 (8\%) patients in each group which was due to deep cortical resection near midline treated accordingly. by coordinating with surgeon to reduce traction, administration of anticholinergic more effective than antiemetic.

* 10 patients in group A $(40 \%$ \} have tight brain which was relieved by increased propofol infusion rate, rescue fentanyl bolus 50 mcg and frusemide.

*There was no awareness in each group, as in both groups depth of anaesthesia was adequate

\begin{tabular}{|c|c|c|c|}
\hline Parameters & Group A (n=25) & Group B (n=25) & p-Value \\
\hline Modified Aldrete Score & $8+/-0.8$ & $9+/-0.2$ & $>0.05$ \\
\hline Mean Hospital Stay(days) & 3.98 & 3.50 & $<0.05$ \\
\hline Patient Satisfaction Score & Satisfactory & Good & - \\
\hline Surgeon Satisfaction Score & Good & Excellent & - \\
\hline $\begin{array}{c}\text { Rescue Fentanyl Requests } 50 \\
\text { mcg/ number) }\end{array}$ & $2+/-1$ & $1+/-1$ & $<0.05$ \\
\hline
\end{tabular}

\section{Table 5. Postoperative Recovery Parameters}

* No Patient in each group had awareness during Asleep period (By PRST score/ BIS). PRST score up to 4\& BIS up to 60-70 were maintained in each group by rescue fentanyl requests $50 \mathrm{mcg}$ per number. More Analgesic requests were in Propofol group. $(\mathrm{P}<0.05)$

* Post operative recovery in form of Modified Aldrete score in group A (propofol) was 8+/- 0.8, \& in group B (Dexmedetomidine) it was 9+/-0.2.(P>0.05)

* In Postoperative period, vitals were with in normal limits in both groups \& no complications noted $(\mathrm{P}>0.05)$

* Mean hospital stay was more 3.98 days in group A whereas 3.50 days in group B. $(\mathrm{p}<0.05)$

* Patients satisfaction score was good with group B(Dexmedetomidine ) \& satisfactory

with group A( propofol)

* Surgeon satisfaction score was excellent with dexmedetomidine (group B) \& good with propofol (group A)

\section{DISCUSSION}

Management of anaesthesia for awake craniotomy varied as evolution in various anaesthetic drugs, technique, as well as gazettes available for Anaesthesia.

Awake craniotomy poses unique challenges especially for the anaesthetist who is faced with an unprotected airway and limited access to the patient due to positioning and pinning of the head.(6)

So, appropriate patient selection, counselling is important for this method.(7)

Patient require sedation or general anaesthesia until the brain is exposed and again at the end of surgery while the cranium is closed.

In present study, both groups patient's premedication was done in same manner.

Goettal N Bhardwaj $\mathrm{S}^{(8)}$ have also compared Dexmedetomidine \& Propofol for conscious sedation for awake craniotomies.

We have used IV Dexmedetomidine/ propofol as they provide sedation without cognitive impairments.(9)

Scalp block was given with $0.5 \%$ Ropivacaine (max. 30 $\mathrm{ml})$ to decrease pain.(10) \& maintaining hemodynamic Stability.(11)

Intraoperative sedation was assessed by Ramsey sedation score RSS was managed around 3 At time of mapping, and 2 after mapping. sedation should be titrated as under sedation cause anxiety, hypertension, tight Brain \& over sedation causes desaturation, problem of correspondence during mapping. $(12,3)$
In both groups airway was managed by second generation LMA (i-gel) as it can be removed with minimum access \& with out causing Laryngeal irritability.(13,14,11)

\section{Scalp Block}

It provides Perioperative \& post operative analgesia. No patient had emergence hypertension. We have to modify our management in 4 patients in Group A (Propofol) as they have desaturation, but they were normal with in $2 \mathrm{~min} .(7,15)$

In both groups Haemodynamic stability was there in asleep, Awake \&Asleep all 3 phases, it shows that dexmedetomidine \& propofol provide minimum change in cardiac parameters in lower doses, as well as scalp block with Ropivacaine provide good quality of analgesia so that patient didn't have tachycardia or hypertension although they were awake arousable, surgery was going on in awake phase \& patients had stable haemodynamics.

\section{NRS Scale}

It was good ( $>8$ in each group) \& comparable in both groups.

Goettal N, Bhardwaj S have also used NRS scale to access cortical Mapping for awake craniotomies (Monitored Anaesthesia Care technique-MAC. They have comparable NRS Score in both groups.(8)

Esenonu et al had also used scalp block with AAA method \& had stable haemodynamics.(16)

Goettal N, Bhardwaj S also record more complications in Propofol group. 
Complications observed in our study were comparable with study of Esenonu CL,(16) in terms of complications, haemodynamics stability, hospital stay.

Postoperative vitals\& postoperative recovery (Modified Aldrete score) was comparable \& with in normal limits in both groups.

Mean hospital stay was less in group B., which was statistically significant $(\mathrm{P}<0.05)$

Scientists are inventing method for outdoor awake craniotomy.(15)

Esenonu have similar mean hospital stay.

Patients satisfaction score \& Surgeon satisfaction score Mean hospital stay, less complications incidences were more in favour of dexmedetomidine group.

\section{Limitations}

1. Limitations of our study were- we have done study in limited number of cases, large scale study required.

2. Study design for day care surgery or early ambulation surgery for uneventful tumour resection should be done.

3. BIS monitoring for depth of Anaesthesia is more useful than RSS, which was available for only 5 patients of each group.

\section{CONCLUSION}

AAA technique for awake craniotomies was successful with propofol or dexmedetomidine. Few adverse effects were noted with propofol group that can be corrected easily.

In a nutshell, AAA technique with dexmedetomidine is more effective than Propofol group for maintenance during awake craniotomies.

\section{ACKNOWLEDGMENTS}

Special thanks to Neurosurgery department, Dr. Mukesh Patel, Dr. Tushar Soni, Dr. Kalpesh Shah, Dr Gopal, All MCH residents, \& Dean of our college Dr. P. R. Patel for continuous inspiration \& team work for the article.

\section{REFERENCES}

[1] Taylor MD, Bernstein M. Awake craniotomy with brain mapping as the routine surgical approach to treating patients with supratentorial intraaxial tumours: a prospective trial of 200 cases. J Neurosurgery 1999;90(1):35-41.

[2] Constello T, Cormack JR. Anaesthesia for awake craniotomy: a modern approach. J Clinic Neuroscience 2004;11(1):16-9.
[3] Randomisation. http://www.randomisation.org

[4] Smadic J, Parso M, Hodzic M, et al. Assessment of depth of anaesthesia: PRST score or Bi Spectral Index (BIS). Med Arth 2011;65(4):216-20.

[5] Alderte JA, Kroulik D. Postanaesthetic recovery score. Anaesthesia Analg 1970;49(6):924-34.

[6] Meyer FB, Bates LM, Goerss SJ, et al. Awake craniotomy for aggressive resection of gliomas located in eloquent brain. Mayo Clinic Proc 2001;76(7):67787.

[7] Blanshard HJ, Chung F, Manninen PH, et al. Awake craniotomy for removal of intracranial tumours: consideration for early discharge. Anaesthesia Analgesia 2001;92(1):89-94.

[8] Goettal N, Bhardwaj S, Venkatraghavan L, et al. Comparison of dexmedetomidine or propofolremifentanyl combination for conscious sedation for awake craniotomy: a prospective randomized controlled trial. British Journal of Anaesthesia 2016;116(6):811-21.

[9] Bekker AY, Kaufman B, Samir H, et al. The use of dexmedetomidiine infusion for awake craniotomy. Anaesthesia Analgesia 2001;92(5):1251-3.

[10] Nguyen A, Girard F, Boudreault D, et al. Scalp block decrease severity of pain after craniotomy. Anaesthesia Analgesia 2001;93(5):1272-6.

[11] Sarang A, Dinsmore J. Anaesthesia for awake craniotomy-evolution of technique that facilitates awake neurological testing. $\mathrm{Br} \mathrm{J}$ of anaesthesia 2003;90(2):161-5.

[12] Rajan S, Cata JP, Nada E, et al. Asleep-awake-asleep craniotomy: complication with general anaesthesia for resection of supratentorial tumours. J Clinic Neuroscience 2013;20(8):1068-73.

[13] Whittle IR, Borthwick S, Haq N. Brain dysfunction following "awake" craniotomy, brain mapping and resection of glioma. $\mathrm{Br} \mathrm{J}$ of Neurosurgery 2003;17(2):130-7.

[14] Hagberg C, Gollas A, Berry JM. Laryngeal mask airway for awake craniotomy in the pediatric patient: report of three cases. J Clin Anesth 2004;16(1):43-7.

[15] Bernstein M. Outpatient craniotomy for brain tumours: a pilot feasibility study in 46 patients. Can J Neurol Science 2001;28(2):120-4.

[16] Eseonu CL, ReFaey K, Tripathi P, et al. Awake craniotomy anesthesia: a comparison of MAC or AAA techniques. World Neurosurgery 2017;104:679-86. 